\title{
Acute inflammatory demyelinating polyradiculoneuropathy
}

INSERM

\section{Source}

INSERM. (1999). Orphanet: an online rare disease and orphan drug data base. Acute

inflammatory demyelinating polyradiculoneuropathy. ORPHA:98916

Acute inflammatory demyelinating polyradiculoneuropathy (AIDP) is an inflammatory neuropathy belonging to the clinical spectrum of Guillain-Barré syndrome (GBS; see this term). 